\title{
DO CUIDADO DA ALMA AO CUIDADO DO CORPO - UMA NOVA COMPREENSÃO DA HISTÓRIA DA ENFERMAGEM
}

\author{
FROM SOUL CARE TO BODY CARE - A NEW COMPREHENSION OF THE HISTORY OF \\ NURSING
}

DEL CUIDADO DEL ALMA AL CUIDADO DEL CUERPO - UNA NUEVA COMPRENSIÓN DE LA HISTORIA DE LA ENFERMERIA.

\section{Maria Itayra Coelho de Souza Padilha ${ }^{1}$}

RESUMO: O estudo aborda o nascimento e desenvolvimento da Companhia das Irmãs de Caridade de São Vicente de Paulo, na França, a partir de 1633. Tem como objetivos reconstruir historicamente o processo de criação da Companhia das Irmãs de Caridade de São Vicente de Paulo e o papel de Luiza de Marillac e Padre Vicente de Paulo neste processo: e discutir a importância da Companhia na proposição de um cuidado de enfermagem pré-profissional, imprimindo as bases do que seria chamado posteriormente de técnicas de enfermagem. É um estudo de natureza sócio-histórica, para o qual utilizarei as idéias preconizadas por Michel Foucault, com relação à análise e discussão dos documentos à luz da análise genealógica. Enfoca principalmente os aspectos que tratam da implementação de uma prática de enfermagem voltada para o cuidado do corpo doente e para a catequização dos pobres e enfermos. Enfatiza-se também a importância de Luiza de Marillac como enfermeira, mestre e guia das demais Irmãs.

PALAVRAS-CHAVE: Enfermagem - História - Luiza de Marillac - Cuidado de enfermagem.

ABSTRACT: This study relates to the birth and the development of the Company of the Sisters of Charity of São Vicente de Paulo in France since 1633. This study has as its objective historically rebuild the process of creation of the Company of the Sisters of São Vicente de Paulo and the role of Luiza de Marillac and Father Vicente de Paulo in this process, and discuss the importance of this Company for the proposal of a pre-professional nursing care, imposing the bases of what would be called later the nursing techniques. It is a study of social and historical nature, to which I will use Michel Foucault preconceived ideas, regarding the analysis and discussion of the documents under the light of the genealogical analysis. This study focuses mainly the aspects that concern to implementation of a nursing practice towards the care of the sick body, and to the catechisation of the poor and the sick people. It focuses also the importance of Luiza de Marillac as a nurse. master and guide to the other Sisters.

KEYWORDS: Nursing - History - Luiza de Marillac - Nursing care.

\footnotetext{
${ }^{1}$ Doutora em Enfermagem. Professora Adjunta do Depto. de Enfermagem da UFSC. Pesquisadora do CNPq.
} 
RESUMEN: El estudio trata del nacimiento y desarrollo de la Compañía de las Hermanas de Caridad de San Vicente de Paulo, en Francia, a partir de 1633. Tiene como objetivos reconstruir históricamente el proceso de creación de la Compañía de las Hermanas de Caridad de San Vicente de Paulo y el papel de Luiza de Marillac y Padre Vicente de Paulo en este proceso; discutir la importancia de la Compañía en la proposición de un cuidado de enfermería pre-profesional, imprimiendo las bases de lo que sería llamado, posteriormente, de técnicas de enfermeria. Es un estudio de naturaleza socio-histórica, para el cual utilizaré las ideas preconizadas por Michel Foucault, con relación al análisis y discusión de los documentos a la luz del análisis genealógico. Enfoca, principalmente, los aspectos que tratan de la implementación de una práctica de enfermería dirigida para el cuidado del cuerpo enfermo y para la catequización de los pobres y enfermos. También se enfatiza la importancia de Luiza de Marillac como enfermera, maestra y guía de las demás Hermanas.

PALABRAS CLAVE: Enfermería - Historia - Luiza de Marillac - Cuidados de enfermería.

\section{CONSIDERAÇÕES INICIAIS}

A história da enfermagem vem sendo construída ao longo dos anos e possibilitando que os olhares sobre a profissão se direcionem para uma ou outra vertente, mas, para qualquer lado que se olhe, percebe-se a nitida influência que as ordens/associaçōes religiosas têm neste processo. A compreensão da enfermagem enquanto profissão se configura nos estudos históricos apenas a partir de Florence Nightingale e seu modelo vocacional, o que de certo modo invalida as demais influências. A idéia de escrever um artigo que tratasse da Companhia das Irmãs de Caridade de São Vicente de Paulo, fundada por Luiza de Marillac e Padre Vicente de Paulo, na França, em 1633, de suas Regras e da instituição de um cuidado que hoje seria denominado de enfermagem, foi levada a termo por considerar que a forma como a administração hospitalar e assistencial que estas impuseram na França e posteriormente na sua difusão pelo mundo, inclusive na Santa Casa de Misericórdia do Rio de Janeiro, marcou o ideário da enfermagem até os dias de hoje e inclusive foi absorvida por Florence Nightingale durante suas viagens para aprender a arte de enfermagem. A compreensão de como esta Companhia iniciou a ritualização dos cuidados de enfermagem ao corpo doente só pode ser efetivada se entendermos a trama inicial na qual se deu o desenvolvimento de um trabalho que posteriormente seria denominado de enfermagem.

Este estudo tem por objetivos:

Reconstruir historicamente o processo de criação da Companhia das Irmãs de Caridade de São Vicente de Paulo e o papel de Luiza de Marillac e Padre Vicente de Paulo neste processo;

Discutir a importância da Companhia das Irmãs de Caridade de São Vicente de Paulo na proposição de um cuidado de enfermagem pré-profissional, imprimindo as bases do que seria chamado posteriormente de técnicas de enfermagem. 
Trata-se de um estudo de natureza sócio-histórica, para o qual utilizarei as idéias preconizadas por Michel Foucault ${ }^{2}$ com relação à análise e discussão dos documentos à luz da análise genealógica. Entendemos que a genealogia, como procedimento explicativo, desconstrói as lutas no interior do discurso, as relações de poder "assinala a singularidade dos acontecimentos fora de toda a finalidade monótona" (Foucault, 1982: 15) e busca descontinuidade onde desenvolvimentos contínuos foram encontrados; registra a singularidade dos eventos fora de qualquer finalidade estática.

$\mathrm{Na}$ história da enfermagem, quando se discute a influência das religiosas sobre a profissão, há um enfoque exacerbado na herança que estas transmitiram das características relativas à bondade, submissão, doação, dentre outras. Pouco se tem refletido nas nuanças do trabalho das religiosas como de uma relação de poder entre estas, aqueles que as contratam, e os subordinados às mesmas. A análise genealógica tem neste estudo o objetivo de identificar e justapor diferenças em busca das manifestações de poder que permeiam todas as relações sociais, esquadrinhando-as, expondo-as e possibilitando um novo olhar para a construção histórica da enfermagem.

As fontes utilizadas para a análise documental foram os escritos de Luiza de Marillac e daqueles autores que tratam de sua história, privilegiando os aspectos relativos à prática de enfermagem desenvolvida pelas irmãs e as relações de poder contidas nos discursos. Para tanto, emprego neste estudo a análise de discurso explicitada por Foucault. Este considera os discursos como uma dispersão, isto é, como sendo formados por elementos que não estão ligados por nenhum princípio de unidade. Cabe à análise do discurso descrever essa dispersão, buscando o estabelecimento de regras capazes de reger a formação dos discursos.

\section{O CUIDADO DO CORPO PARA SALVAR A ALMA}

No século XVII, é fundada uma das organizações de religiosas leigas e que mantém seu trabalho até os dias de hoje, que é a Companhia das Irmãs de Caridade, fundada pelo Padre Vicente de Paulo (1580 - 1660), e Luiza de Marillac (1591 - 1660), no ano de 1633, na França.

Padre Vicente de Paulo era francês, descendente de uma familia pobre, que conseguiu estudar e receber o sacerdócio aos 20 anos de idade, na Ordem católica de São Francisco de Assis, e desde sua introdução na igreja preocupava-se com a situação de abandono dos pobres franceses. Luiza de Marillac era também francesa, proveniente de família abastada e influente, e que, após enviuvar, resolveu dedicar sua vida aos pobres, aos doentes e aos necessitados.

${ }^{2}$ Ver: FOUCAULT, M. Microfísica do poder. 3 ed. Rio de Janeiro: Graal, 1982. Cap. XI e XII. A arqueologia do Saber. 4 ed. RJ: Forense Universitária, 1995. Cap. II e III. 
O trabalho sacerdotal do Padre Vicente de Paulo desenvolveu-se, principalmente, a partir de sua instalação em Paris, na paróquia de Clichy, por ordem do Bispo, sendo mais tarde designado para Chântillon-les-Dombes, na Borgonha, onde realizou a evangelização dos camponeses da região e fez parte da capelania da casa do General de Gondi, responsabilizando-se durante 12 anos pela educação dos três filhos da familia e pregação e catequese nas terras de Gondi, apoiado principalmente pela Senhora de Gondi. Este trabalho permitiu-lhe a criação de três obras de grande importância social:

1 - A obra das missőes nos campos pregada pelos padres, fundada em 1617.

2 - A Confraria da Caridade, fundada em 1617;

3 - A catequese dos criminosos condenados às galés, fundada em 1625.

O trabalho desenvolvido por Padre Vicente de Paulo permitiu que este se relacionasse com as damas da sociedade, viúvas ou não, preocupadas em ocupar seu tempo com tarefas religiosas e caritativas, as quais Ihes permitiam utilizar seu tempo de uma forma útil e seu dinheiro para ganhar um lugar no céu. Padre Vicente conseguiu com isso obter seu apoio e participação efetiva nas obras de caridade a que se propunha.

A primeira Confraria da Caridade foi fundada em Chântillon des Dombes, em 23 de agosto de 1617, ainda sob os auspícios da familia de Gondi, decorrente da necessidade, sentida pelo Padre Vicente de Paulo, do apoio de pessoas leigas no trabalho desenvolvido junto aos pobres, principalmente, devido à falta de recursos financeiros que permitissem um cuidado mais efetivo no que se relacionasse a roupas, mantimentos, asilo e visitas domiciliárias onde se realizavam a catequese do povo. Após extensas discussões entre o padre e as senhoras da sociedade, resolveram fundar uma Companhia denominada Confraria da Caridade, cuja finalidade era a de "Assistir os doentes pobres, espiritualmente para morrerem em estado de graça, ou, recuperando a saúde, para viverem sem ofender a Deus, e corporalmente, proporcionando-lhes remédios e alimentos" (Castro, 1936: 62).

As Senhoras da Caridade participavam ativamente da Confraria com o seu poder financeiro, no auxilio à construção cristã. Destas eram exigidas algumas características ou qualidades para o ingresso na Confraria, ou seja: uma total "abnegação", um fervoroso "zelo" em promover o bem dos outros, além de uma "humildade" profunda e uma "prudência" constante em beneficio da caridade; por isso havia uma certa preferência pelas viúvas ou solteiras (Castro, 1936: 62).

A palavra pobre é geralmente reservada aos indigentes, aos aleijados e aos desfavorecidos de todos os tipos, acompanhada de substantivos significantes de aflição (fome, mendicância, exaustão) ou de sentimentos (piedade, misericórdia) (Mollat, 1989: 152). O principal ponto dos Estatutos da Confraria da Caridade é a visita aos enfermos, que trata da entrega dos remédios e alimentos. Cada serva dos pobres preparará o jantar e servirá os pobres durante um dia inteiro. A priora será a primeira, a tesoureira a segunda, e assim por diante, até a última. Aquela que estiver trabalhando receberá da tesoureira o necessário para o sustento dos pobres, preparará a comida e a levará ao enfermo. Nesta ação, 
evidencia-se o rodizio de tarefas como uma medida para descentralizar o poder sobre cada atividade e como uma forma para que cada uma se penitencie nas melhores e nas piores ações (Castro, 1936: 63).

Paralelamente, Luiza de Marillac, denominada Mademoiselle Le Gras, devido ao sobrenome do marido, Antônio Le Gras, que morre em 1625, depois de 12 anos de casamento, desenvolvia um trabalho caritativo junto aos pobres de sua paróquia, levando-lhes comida, roupas, curativos e mortalha aos mortos. A partir da morte do marido, Luiza de Marillac passa a distribuir seu tempo entre o filho Miguel, o trabalho junto aos pobres de sua paróquia e as obrigações religiosas.

A partir de 1623, o Padre Vicente de Paulo tornara-se o seu diretor de consciência, ou seja, aquele com quem se confessava e também pedia conselhos sobre como deveria levar sua vida pessoal e caritativa. Em 1629, este a convida para assumir a Confraria em Paris no papel de "visitadora e zeladora da caridade", funções por ele estabelecidas nas cidades vizinhas, considerando o seu "espírito benevolente" e com vontade de servir a Deus de forma integral, já que era viúva e poderia viajar "supervisionando" as Obras de Caridade já fundadas, e fundando outras, [que era o grande interesse do padre Vicente de Paulo] (Castro, 1936: 83) .

O trabalho de Luiza era reunir os membros das Confrarias para ler e explicar o regulamento, observando se o mesmo estava sendo seguido e arrebanhar novos membros. O auxílio material distribuído por ela servia de veículo para penetrar na casa dos pobres e ali pregar a catequese do amor a Deus sobre todas as outras coisas terrenas, e através disso pode-se considerar que já se realizava em pleno século XVII um trabalho precursor de assistência social nos domicilios.

Vemos a partir destas ações a difusão dos procedimentos disciplinares, fora das instituições fechadas, como de focos de controle disseminados na sociedade, na catequese e disciplinamento das populações. Foucault enfatiza que os objetivos destas organizações passavam pelos conceitos religiosos, de conversão e moralização; econômicos, de socorro e incitação ao trabalho; ou políticos, como uma forma de impedir/lutar contra o descontentamento e a agitação (Foucault, 1987: 182).

As Confrarias de Caridade, na província, floresciam, principalmente pelo grande envolvimento das camponesas no trabalho junto aos pobres, o que não acontecia em Paris, por serem as Confrarias compostas de senhoras da mais elevada nobreza, que não se dispunham muito prontamente a visitar os pobres nos seus domicilios e nos hospitais. A peste infectava os hospitais e os casebres da plebe, e os maridos temendo por suas esposas proibiam-lhes o exercício da caridade. Havia abundância de esmolas, mas falta de braços.

Sendo assim, havia necessidade de encontrar auxiliares que visitassem os pobres nas casas e nos hospitais para levar-Ihes alimentos e roupas, bem como para auxiliá-los nas doenças. Padre Vicente e Luiza de Marillac pensaram, então, em resolver este árduo problema, pois sabiam que era necessário que houvesse mulheres que se responsabilizassem unicamente pelo "pão dos 
pobres enfermos, alimentação e os remédios segundo a exigência de suas enfermidades" (Castro, 1936: 216) de forma pacífica, sem outros compromissos que as impedissem de realizar estas tarefas.

A compreensão de que a perfeição cristã somente poderia ser alcançada por aquelas pessoas dispostas a abrirem mão de todos os prazeres terrenos, praticando as três virtudes consideradas essenciais para este fim, que eram: a "pobreza, a castidade e a obediência", as quais praticamente excluiam aquelas senhoras casadas que moravam em amplas e ricas residências. A forma encontrada para resolver a questão foi a de chamar moças camponesas de Paris e arredores, que mostrassem desejo de servir aos pobres de cada Confraria da capital. A razão pela qual padre Vicente de Paulo e Luiza de Marillac chamaram estas aldeãs pode ser compreendida na observação de que ambos, durante suas andanças visitando as Confrarias da Caridade, haviam encontrado, pelo caminho, muitas "donzelas sem inclinação para o casamento nem recursos para abraçar a vida religiosa, mas dispostas a se dedicarem às obras de caridade" (Vaessen, 1949:54).

\section{O CUIDADO DO CORPO COMO TAREFA}

O corpo tornava-se alvo de novos mecanismos de poder, oferecidos como novas formas de saber. Corpos sem queixas, sem ideais, manipuláveis e treináveis para uma causa justa (a de servir e curar o próximo). Um corpo que se sujeitasse às regras de conduta rígidas e exigentes, formadoras do espírito da caridade cristã.

O berço da Companhia das Irmãs de Caridade localizava-se na rua São Vitor, número 43 , numa casa pequena, com duas janelas de frente e uma porta baixa, dando acesso para um corredor escuro. Essa casa estreita, mas bastante comprida, foi o local em que as quatro primeiras humildes camponesas se reuniram, em 29 de novembro de 1633, para receberem, na oração e na união de suas almas, o espirito de Deus e a missão de iniciar um novo tipo de assistência aos pobres e enfermos (Castro, 1936: 82).

A primeira superiora da Companhia foi Luiza de Marillac e permaneceu como tal até o dia de sua morte. Sua função era receber as jovens aldeãs que quisessem consagrar-se a Deus, ensiná-las a curarem as feridas e mostrar a melhor forma de tratarem dos doentes, fazer o serviço dos pobres, formá-las na piedade e, quando necessário, ensiná-las a ler e a escrever. Tinha a liberdade de mudá-las de paróquia e de ofício, além de despedir as que não tivessem as qualidades [vocação] necessárias para estas funções.

A intenção inicial era a da manutenção do trabalho executado até então pela Confraria da Caridade, que tinha como finalidade ajudar nas paróquias e domicilios dos pobres e doentes, suprindo a falta de Senhoras da Caridade, ou então realizar as tarefas rejeitadas pelas mesmas. O trabalho nos hospitais aconteceu em decorrência dos anteriores. 
Depois dos primeiros meses, Luiza de Marillac escreveu o primeiro esboço do regulamento a ser seguido pelos membros da Companhia. Segundo consta, padre Vicente estava doente e por isso não foi consultado com antecedência, mas assim afirmou quando esta enviou-lhe o que havia escrito: "Deus assim quis, para que eu não ponha minha foice na vossa seara" (Castro, 1936: 84).

O treinamento deveria ser de poucas palavras, nenhuma explicaçăo e o máximo de silêncio, interrompido por exercícios de catequese, cuidados domésticos e caridade. Um simples olhar, gestos, palmas, deviam "significar em sua brevidade a técnica de comando e a moral da obediência" (Foucault, 1987: 149).

O exercício da disciplina supõe um dispositivo que obrigue pelo "jogo do olhar" (Foucault, 1987: 158); uma forma onde as técnicas que permitem ver induzam a efeitos de poder. É ao mesmo tempo silencioso e "discreto", mas absolutamente indiscreto porque está presente o tempo todo, em cada canto e lugar. Uma irmã supervisiona e controla a ação da outra e é controlada por esta, e todas são "olhadas" e "vigiadas" pela Superiora.

Durante os primeiros dez anos, a Companhia não tinha Regulamento definitivo e pouco a pouco o que era prática tornava-se tradição. Tinha como primeiro princípio, aquele que Deus the entregou, ou seja: "nas pessoas dos pobres velhos, crianças, doentes, prisioneiros $\theta$ outras mulheres, todos os serviços, sejam corporais, sejam espirituais,(...) e ainda que não sejam religiosas (Ausart, 1780:221), devem portar-se como tal, guardando uma vida perfeita de recolhimento, castidade e abstenção de toda a leviandade terrena. Além disso, deveriam guardar-se ao máximo de qualquer contato com o sexo masculino, mesmo quando elas próprias necessitavam de cuidados médicos, ou quando iriam cuidar de homens doentes. Deveriam, nestas ocasiões, serem acompanhadas por outra irmä ou senhora do local.

Com relação aos doentes que cuidavam, deveriam "levá-los para confessarem seus pecados" antes de morrerem e, caso recuperassem a saúde, eram induzidos a consagrarem-se a Deus, o qual foi o responsável pela sua recuperação. O plano de conduta das Irmãs de Caridade prescrevia sempre o serviço espiritual aliado aos cuidados corporais de enfermagem, devendo ambos serem realizados com muita "humildade". Os cuidados corporais eram compreendidos como uma forma de chegar ao espirito dos homens e assim catequizá-los.

Todas as candidatas a serem Irmãs de Caridade deveriam aprender as três virtudes formadoras da alma das Irmäs de Caridade: a humildade, a simplicidade e a caridade. O espirito de doação, a abnegação e a castidade despontam como prioridades nas exigências àquelas que iriam cuidar do corpo do outro e naquelas que exerceriam o trabalho de enfermeiras. O cuidado, mais uma vez, é entendido como um ato de caridade e um modelo vocacional religioso, em que o apelo explicito de servir e o espírito de serviço vão se constituindo.

A rotina cotidiana das Irmãs de Caridade era acordar às cinco horas (o horário foi mudado para as quatro quando as Irmãs assumiram o serviço do 
Hôtel-Dieu) e fazer a oração da manhã. Após, as Irmãs que estavam trabalhando "de dia" para servir aos pobres dirigiam-se à casa da senhora designada para a caridade daquele dia e cozinhavam a ração dos pobres, para a distribuirem às $9 \mathrm{~h} 30 \mathrm{~min}$. As outras repartiam depressa os remédios antes da missa, que acontecia às $9 \mathrm{~h}$. Depois da missa, as que estavam em casa aprendiam a ler e a trabalhar com agulha. Ao meio dia, um leve almoço, precedido de uma leitura espiritual. Depois de um pequeno recreio, as que estavam encarregadas dos remédios buscavam, na casa dos médicos, as receitas e, na casa da Senhora de Caridade que fora designada para o dia seguinte, a tarefa daquele dia. Além disso, aprendiam como cuidar dos doentes, realizar sangrias e outros cuidados de enfermagem. A noite, liam o evangelho e tinham aulas de leitura e catecismo. Nomeavam-se algumas Irmãs para os oficios de despenseira, roupeira e preparo dos remédios dos pobres [boticária] (Boavida, 1915).

A ocupação completa do tempo visava evitar os desvios e o desperdício de tempo de cada uma das irmãs, constituindo-se em uma forma de ocupar o corpo e os pensamentos de cada Irmã para manutenção da moral e da catequese. Cada instante deveria ser intensificado e controlado, como se o tempo em seu fracionamento fosse inesgotável; ou se pelo menos, por uma organização interna cada vez mais detalhada, pudesse pender para um ponto ideal onde o máximo de rapidez encontra o máximo de eficiência. O ritmo do tempo era marcado pelo toque do sino, indicando a tarefa a ser realizada [acordar, ir à missa, comer, orar], sincronizando as ações e estabelecendo um padrão de comportamento.

As atitudes das Irmãs de Caridade deveriam ser de submissão e sujeição àquelas que assumiam a responsabilidade pelo cuidado, ou seja, as senhoras da Confraria da Caridade, as quais determinavam as tarefas a serem desempenhadas pelas Irmãs. O trabalho das Irmãs era inicialmente 0 de preparar e levar os alimentos aos doentes, além de os ajudarem a se alimentarem quando necessário. As Senhoras da Confraria cabia o trabalho de instruir os doentes a confessarem seus pecados e catequizá-los.

De uma forma simplista ia se estabelecendo uma divisão social de classe e de trabalho, como se evidencia a seguir quando algumas Senhoras da Confraria se ressentem da presença das Irmãs "pessoas de modos simples" e passam a propagar a idéia de que aquele serviço só deveria ser realizado por pessoas "formadas de bom-tom, e que só parisienses estavam à altura daquele serviço".

A partir dai ficou oficializada a separação entre o cuidado corporal e o cuidado espiritual, sendo que este último ficaria sob a estrita responsabilidade das Senhoras da Confraria, as quais fariam um revezamento da atividade de três em três meses. A mola mestra no cuidado aos doentes no hospital era a salvação das almas, tanto dos pobres no momento da morte quanto daqueles que cuidavam dos mesmos. O espírito de servir e o compromisso com a caridade eram suficientes para a identificação daquelas que seriam "enfermeiras", e reconhecidas como tal pelas suas atitudes. Percebe-se que o cuidado corporal era entendido como o de menor importância e o cuidado espiritual, ao contrário, era o mais valorizado e portanto deveria ser realizado por pessoas de alto nivel social e religioso. 
O trabalho desenvolvido pela Confraria e pelas Irmãs de Caridade no HôtelDieu logo ficou conhecido em toda a França. A presidenta da Confraria, senhora Goussault, que visitava e se responsabilizava pelo auxilio ao hospital São João de Angers ${ }^{3}$, ao qual concedia esmolas e doações, decidiu colocar Irmãs de Caridade neste hospital. Antes de concordar, os administradores do hospital foram a Paris conhecer o serviço prestado pelas Irmãs aos doentes no Hôtel Dieu e insistiram para que estas se responsabilizassem por todo o regime interno do hospital. Em $1^{\circ}$ de fevereiro de 1640, é assinado o contrato entre as irmãs e os diretores do estabelecimento. Este contrato foi o primeiro e serviu de modelo a muitos outros.

Foi a partir deste hospital que as Irmãs passaram a assumir total responsabilidade pela administração e pelos cuidados prestados aos doentes, residindo inclusive no local. O hospital de Angers era a casa modelo e abriu a série das grandes fundações, inicialmente na França e, a partir do século XIX, no mundo.

A disciplina como uma "anatomia politica do detalhe" (Foucault, 1987: 129) já se achava presente no primeiro regulamento apresentando-se como uma forma clara de coibir quaisquer interferências na rotina estabelecida e uma garantia de que o trabalho seria cumprido. Os próximos tratados tiveram algumas modificaçōes, mas mantiveram os pressupostos iniciais, associando a disciplina do minúsculo à mistica do cotidiano. Nada é insignificante e deve ser esquecido, desde a obediência aos superiores de forma irrestrita, até o hábito [uniforme] que devem utilizar, demonstrando que a enfermagem desde esta época é uma profissão em que as minúcias e os detalhes a constroem e fazem parte do seu cotidiano.

No dia da assinatura do contrato, as Irmãs foram instaladas no hospital e em poucos dias toda a população da cidade de Angers vinha visitar 0 estabelecimento: as salas tinham sido caiadas e arejadas, cada doente tinha o seu leito, 110 para os homens e 90 para as mulheres e mais alguns para casos particulares. Por toda a parte, reinava o asseio, a ordem, a vigilância e a caridade (Castro, 1936: 143).

O hospital era um local de assistência aos pobres, mas também de "separação e exclusão", isto é, o pobre tem necessidade de cuidados por ser pobre, mas também pode ser portador de algo contagioso. "Por estas razões, o hospital deve existir para recolhê-lo, mas também para proteger os demais do perigo que ele encarna" (Foucault, 1982: 101). O personagem hospitalizado até o século XVIII não é o doente que precisa ser curado mas o pobre que deve ser assistido física e espiritualmente para morrer em paz.

O regulamento a ser seguido pelas Irmãs de Caridade enfermeiras se assemelhava ao original, acrescentado do SERVIÇO DOS DOENTES.

\footnotetext{
${ }^{3}$ Esse hospital foi fundado, em 1160, por Henrique II, Conde d' Anjou e Rei da Inglaterra. Fora administrado espiritualmente pelos Agostinianos, mas, no século XVII, estava sem assistência de ordem alguma. CASTRO, 1936: 139.
} 
(...) farão suas camas, porão em ordem os dormitórios, apresentarão os remédios e darão o almoço. No correr do dia uma vigilância contínua sobre os doentes para atenderem aos seus menores reclamos, o alimento nas horas marcadas, as poções quando tiverem sede, com algumas pastilhas que Ihes adocem a boca. Ao anoitecer, à sete horas, o deitar de todos os doentes, premunidos com um pouco de vinho e com algumas doçuras para o que possam necessitar de noite. Das oito horas em diante, vigia uma Irmã em todas as salas pronta a acudir ao menor gemido ou chamado" (Boavida, 1916 :264).

Com o passar dos anos, a Companhia das Irmãs de Caridade foi expandindo seu poder pastoral para além dos domínios franceses. Para se ter uma idéia desta expansão, vale ressaltar que, em 1815, o número de casas passava de 150 e apenas 13 anos depois era de 283.

\section{A ARTE DA DOCILIDADE}

Na história de Luiza de Marillac, o padre Jerônimo de Castro (1936) traça um estudo sobre as qualidades exigidas por esta e pelo padre Vicente de Paulo na escolha daquelas que desejavam ser Irmãs de Caridade. Eram elas:

1- a vocação natural de praticar todas as virtudes do estado religioso; e

2 - a capacidade física e moral para ser serva dos pobres.

As condições de admissão das candidatas a Irmãs de Caridade reforçam estas qualidades e colocam algumas exigências que demonstram a importância dos corpos sãos para o exercício da caridade e para serem utilizados e empregados na sua totalidade, para que se integrem ao "bom emprego do corpo" e ao bom "emprego do tempo" (Foucault, 1987: 138). Luiza considerava esta uma vocação pesada e, portanto, não seria qualquer moça que se adaptaria a ela.

As condições de admissão eram de que as moças deveriam: ser filhas legítimas de familia honesta; ser de cor branca e ter pelo menos $1,50 \mathrm{~cm}$ de altura; ter idade compreendida entre 16 e 28 anos; ter forças suficientes, instrução, no mínimo primária completa, boa reputação e estar, sobretudo, resolvida a servir a Deus, ser muito SUBMISSAS aos superiores, aceitando indiferentemente qualquer trabalho, estar dispostas sempre a irem para o lugar que a SUPERIORA lhes designasse e observar fielmente o regulamento da Companhia (Vaessen, 1949: 205). A exigência inicial de instrução das candidatas năo foi levada a termo, provavelmente pelo grande índice de analfabetismo à época, encarregando-se Luiza de ensinar a ler aquelas que ainda não o sabiam.

As demais qualidades eram prioritárias e indicavam um processo seletivo exigente que as diferenciaria de todas as pessoas que prestavam serviços, principalmente nos hospitais ou nos domicilios. Estas qualidades marcariam para sempre o ideário da enfermagem na escolha daquelas que deveriam seguir esta 
profissão, culminando basicamente com Florence Nightingale, quando criou e sistematizou o ensino de enfermagem dentro de exigências semelhantes a estas.

Reforçando a idéia da seleção apurada das Irmãs, percebe-se em correspondência de Luiza de Marillac para outra Irmã, datada de 1655 , que a mesma insistia com a Irmã lembrando-a que, ao selecionar candidatas à Companhia, deveria "verificar se as duas jovens estão cientes de tudo que deverão fazer e sofrer na Companhia, se possuiam a PUREZA DE INTENÇÃO requerida para nela entrar (...) e já vos deste conta de que NÃO TENHAM NENHUM DEFEITO FÍSICO, nem de nascimento e não tem pai nem mãe que delas necessitem"(Santa Luiza de Marillac, 1655: 537). Em suma, deveriam ser moças sadias que pudessem libertar-se de todas as ligações familiares a fim de serem preparadas para seguir as regras da Companhia, além de serem deserotizadas para cuidar do corpo do outro como um ser ausente de todos os desejos terrenos.

A submissão reforça o processo de disciplina, produzindo corpos dóceis, maleáveis, deserotizados, que podem ser aperfeiçoados e transformados para a sujeição. As atividades desenvolvidas com as Irmãs (enfermeiras, educadoras, visitadoras, etc.) durante o noviciado e as exigências da admissão compreendem a dominação de seus corpos através da ênfase no seguimento das "regras", na. utilização adequada do tempo e pelo disciplinamento das ações. O poder disciplinar "fabrica corpos submissos e exercitados, corpos 'dóceis'. A disciplina aumenta as forças do corpo (em termos econômicos de utilidade) e diminui essas mesmas forças (em termos políticos de obediência)" (Foucault, 1987: 127).

O reforço diário na deserotização do corpo das Irmãs é enfocado no fato de que a Irmã enfermeira jamais poderia visitar ou receber a visita de alguém do sexo masculino sem a companhia de outra Irmã, mesmo se este alguém fosse o seu médico. Quanto ao termo "castidade", padre Vicente de Paulo achava-o "pouco expressivo" e o substituia por "pureza", por entendê-lo com sentido mais amplo ${ }^{4}$. Etimologicamente, não existem muitas diferenças entre os termos, considerando que 'casto' também é significado de puro; talvez a amplitude do termo 'pureza' a que o padre Vicente de Paulo se referia fosse decorrente do entendimento de limpeza, brancura, sem mistura, e mais amplamente, de santidade.

A honra configurava-se no imaginário da época como explicitamente vinculada à sexualidade da mulher, isto é, "ao controle que ela desenvolvia sobre os impulsos e desejos do próprio corpo"(Algranti, 1993: 110). Estes desejos necessitavam ser coibidos na sua totalidade, já que estas deveriam cuidar do corpo do outro sem vê-lo.

4 CUNHA, A. G. Dicionário etimológico nova fronteira da língua portuguesa. Rio de Janeiro: Nova Fronteira, 1996. O termo 'castidade' refere-se à qualidade ou ao caráter de casto; e 'pureza', ao que é sem mistura, nem alteração. 
$\mathrm{Na}$ sua origem, os termos 'honra' e 'virtude', qualidades esperadas e exigidas das Irmãs, têm pouco em comum, ao menos no sentido etimológico ${ }^{5}$. Seus significados aproximam-se no século XIII, conduzidos pelo cristianismo, e seus conceitos são vinculados muito mais pela prática social do que pela sua lógica interna, embora 'virtude' e 'honra' fossem qualidades sempre esperadas daquelas que serviam ao próximo ${ }^{6}$. Para as mulheres, eram características que indicavam um bem que estas possuiam e deveriam preservá-las cuidadosamente e virtuosamente através da castidade. "Ela era um dos pilares da própria existência e transparece de forma eloqüente" (Elias, 1994: 155).

No cotidiano das Irmãs de Caridade a decência era um detalhe focalizado a partir do ponto de vista judaico-cristão, onde a virtude era quase sinônimo de honra, o bem maior de todas as mulheres, principalmente das religiosas e castas. Etimologicamente, a palavra decência é relacionada à honra, ao pudor e ao decoro. Mas também considera-se a decência como sinônimo de honestidade. Ser decente, então, é ser conveniente (Cunha, 1989). Os conceitos de decente ou não são socialmente aprendidos, e estas noções estendem-se ao discurso, proibindo-se palavras, frases, referências, olhares, "como é muito fácil desviar-se das boas práticas e resoluções, é necessário acautelar-se, principalmente para não caírem em maledicências." (Santa Luiza de Marillac, sd:852). Não era honroso ou conveniente que as Irmãs tivessem qualquer contato com um corpo nu, para não correrem o risco de romperem com os votos de recolhimento e virgindade que haviam assumido, devendo "olhar os doentes como se fossem seus filhos"(Santa Luiza de Marillac, sd: 853).

Assim, para evitar que as Irmãs "cedessem aos vivos", isto é, se deixassem levar pelas tentaçōes do corpo, era necessário a manutenção do olhar disciplinador de umas sobre as outras de uma forma "bastante discreta para não pesar como uma massa inerte sobre a atividade a disciplinar e não ser para ela um freio ou obstáculo, integrar-se ao dispositivo disciplinar como uma função que Ihe aumenta os efeitos possiveis" (Foucault, 1987: 156).

As Irmãs aceitavam passivamente não apenas a necessidade de companhia constante, "não sairão de casa senão duas a duas(...) não se deterão pelo caminho a conversar com ninguém" (Santa Luiza de Marillac, sd: 836), como o olhar disciplinador, como se este processo de sujeição explícito ao vigiar funcionasse como uma proteção a elas, como um exercício de disciplinamento para as enfermeiras. Sempre poderiam ser vistas e vigiadas, esquadrinhadas

\footnotetext{
${ }^{5}$ A palavra honra provém do latim honor que, sob esta forma, dá origem a honorário, honorifico. Do genitivo honoris, produz honra e derivados: honrado, honraria. Virtude, origina-se de vir, substantivo latino que significa "homem forte". GOIS, C. Dicionário de raizes e cognatos da língua portuguesa. Rio de Janeiro: Francisco Alves, 1921: 31.

${ }^{6}$ CUNHA, A. G. - 'virtude' é a disposição firme para a prática do bem (séc. XIII) e 'honra' é respeito, dignidade, crédito (Séc. XIV).
} 
como no panóptico estudado por Foucault, que "funciona como uma espécie de laboratório de poder"7.

O que reduz a importância da clausura é a permanente possibilidade do olhar, da vigilância de uma Irmã sobre a outra, que as leva a agir e atuar como corpos continuamente vigiados e, portanto, dóceis. É a clausura implícita, que existe pela própria idéia de seguimento das regras de humildade, castidade e confissão semanal ao diretor de consciência.

As cartas de Luiza de Marillac às demais Irmãs de Caridade espalhadas pela França indicam o que era esperado destas Irmãs (enfermeiras) nos hospitais, em termos de atribuições ${ }^{8}$.

"(...) se podereis acabar de ensinar a uma irmã que já sabia preparar remédios caseiros e outros, a manipular medicamentos, porque nos seria dificil enviar-vos, pelo menos de imediato, uma que já esteja habilitada"m.

"(..) não deixeis de lavar os pés dos doentes ao serem admitidos, de pôr-lhes roupa limpa e tratá-los com docura e caridade. É obrigação vossa cuidar para que tenham remédios e alimentos à hora certa e que as irmãs observem com pontualidade, o seu regulamento" "7o.

"(...) estarão bem atentas a que os mais graves se lavem a boca ou se lhes faça a higiene bucal com freqüência, a fim de evitar úlceras contagiosas. "II

"(...) cada irmã por rodizio, cuidará de prover as necessidades que os enfermos possam ter durante a noite(...). Quando a necessidade do doente requeira, velarão a noite inteira, por turno. "12

"Por causa dos perigos das sangrias e purgantes (...) se informarão do tempo em que estão doentes e começarão a lhes dar lavagens ou sangrias, se estiverem sentindo enjôo. Se as febres continuarem, deverão repeti-las 3 a 4

${ }^{7}$ FOUCAULT, M. Idem, p. 177. O panóptico de Bentham, é uma forma de arquitetura que permite àquele que vigia ver sem ser visto, o tempo todo, numa construção em anel na periferia, tendo ao centro uma torre com amplas janelas que se abrem sobre a face interna deste anel. As celas ficam na área periférica e a forma das janelas permite que a luz as atravesse de lado a lado; assim a possibilidade de ser visto ocorre sempre. O poder é visivel, mas inverificável.

${ }^{8} \mathrm{O}$ regulamento da Companhia tratava dos aspectos mais gerais da mesma e năo do cuidado especifico dos doentes. Este foi elaborado em 1645. COSTE, Pierre. La congregation de la mission. Paris: Lecoffre. sd. cap. XIII. p. 551 .

9 Idem, p. 326 . Carta de 1649 para uma Irmã do Hospital Sāo Renato em Nantes.

${ }^{10}$ Idem,p.332, de 1649. Carta a Irmã Bárbara Angiboust, em São Dionísio.

11 Idem, p. 858. Sobre o modo de tratar os doentes no Hospital Saint-Denis.

12 Idem, p. 859.

R. Bras. Enferm. Brasília, v. 51, n. 3, p. 431-446, jul./set., 1998 
vezes. Se a febre persistir ainda, picarão no pé, depois voltarão a fazê-lo no braço até que ceda (...)"

O ensino das artes de enfermagem é transferido da Superiora às outras, através de cartas explicativas, ou então de uma Irmã para outra, demonstrando que não havia ainda nenhum manual escrito sobre estas ações. Esta forma simplista de transmitir o saber empírico de enfermagem não demonstra uma organização técnica do cuidado de enfermagem, mas a sua implementação se aproxima do que seria chamado futuramente de "técnicas de enfermagem".
"(...) a dita irmã servente será também encarregada de mandar embora os doentes, com mansidão e caridade, porém com PRUDEN NCIA E IUSTICA "7t
"(...) Encarregasse-a de todas as provisões indispensáveis a casa,(...) calculando bem o tempo a fim de que nem os doentes nem as irmãs se vejam prejudicados no serviço do hospital. "15

As Irmãs que cuidam dos doentes não são denominadas enfermeiras e nem o seu cuidado é chamado de enfermagem, embora o exerçam como tal. A razão da não utilização do termo pode ser decorrente da divisão das tarefas impostas pelas regras da Companhia e da necessidade de fragmentação do trabalho. A Irmã Enfermeira cuidava dos doentes, mas exercia um trabalho suborcinado à Irmã Servente, que também era enfermeira, e à Boticária, cujo trabalho era de grande responsabilidade junto aos doentes, pois decidia o preparo dos medicamentos, sua quantidade, indicava as dietas a serem seguidas, quando deveriam ser realizadas as sangrias e de que forma deveriam ser feitas, além de ensinar o ofício às outras Irmãs. Embora realize cuidados, não é considerada enfermeira, porque no regulamento das Irmãs consta que esta deveria "zelar para que a irmã chamada enfermeira, cumpra bem sua obrigação" (Santa Luiza de Marillac, 1645: 872), que deveria ser provavelmente o da execução dos cuidados indicados pelas Irmãs Servente e/ou Boticária.

No século XVII, o médico está inserido no espaço hospitalar não de forma dominante mas sim como um coadjuvante do trabalho desenvolvido pelas Irmãs, o que demonstra claramente o quanto este, naquele momento, não era a figura principal no cuidado aos doentes.

" $A$ irmã boticária (...) avisará ao médico e cirurgião a fim de que visitem os doentes e terá particular obrigação de comunicar à irmã servente o estado dos doentes.(...) A referida irmã boticária ou alguma outra irmã sangrará também os doentes, quando o cirurgião não estiver presente no momento necessário, fazendo também o curativo das feridas. "16.

13 Idem, p. 852, sd. Observação sobre as REGRAS. Irmã a serviço nas aldeias.

14 Idem, p. 860. (grifo meu)

${ }^{15}$ Idem, p. 860. (grifo meu)

${ }^{16}$ SANTA LUIZA DE MARILLAC, idem p. 861, 1645. Regras p/ o Hospital Saint-Denis 
A presença do médico era solicitada quando as Irmãs não conseguiam ou não sabiam como resolver o problema do doente, e isto significa que elas decidiam também quando a presença dele era necessária e até mesmo para que tipo de necessidade.

Estes discursos vão ao encontro do que Foucault coloca acerca dos hospitais: que, até o século XVIII, o médico não permanecia no local, e no caso das citações das Irmãs, este era chamado para atender ao doente no momento em que este era internado ou necessitava de algum cuidado médico. $A$ inspeção então era "descontínua e rápida" (Foucault, 1987: 166) e o doente não era visto ainda como objeto de saber e conseqüentemente de poder médico.

\section{CONSIDERAÇÕES FINAIS}

Um fato que fica evidente na análise dos documentos escritos por Luiza de Marillac e que conduziu a prática de enfermagem até ao Brasil é a exigência explícita acerca do comportamento das Irmãs enfermeiras e de todas as demais, o qual deveria ser sempre marcado e moldado pela "humildade, simplicidade, modéstia e caridade" como virtudes que deveriam compor seu espírito, além de reforçar a "mansidão" entre elas e com os doentes, praticando a "tolerância $e$ cordialidade", tudo isso com grande "submissão e verdadeira humildade". Estas características predominantes no caráter das Irmãs de Caridade e que foram sendo passadas através dos séculos pelas "regras" da Companhia possibilitaram a construção de um perfil dócil e delicado no cuidado com os doentes e com as demais pessoas. Corpos que seguem e acatam as normas são corpos obedientes e submissos, prontos para assumirem o papel que lhes cabe no hospital.

\section{BIBLIOGRAFIA E FONTES}

1. ALGRANTI, Leila Mezan. Honradas e Devotas: Mulheres da Colônia. Condição Feminina nos Conventos e Recolhimentos do Sudeste do Brasil, 1750-1822. Rio de Janeiro: José Olympio; Brasilia: Edunb, 1993.

2. AUSART, A. J. S.. Vicent de Paul (l'espirit de) ou modèle propocé a transles ecclisiastiques dans ses virtus, cés actions et ces paroles. Paris, 1780.

3. BOAVIDA, Padre Luiz Gonzaga. Vida da venerável Luiza de Marillac. Rio de Janeiro: Typ. Besnard Frères, 1915.

4. CASTRO, Jerônimo, C. M.. Vida de Luiza de Marillac - fundadora das Irmãs de Caridade. Petrópolis: Vozes, 1936.

5. CUNHA, Antônio Geraldo da. Dicionário Etimológico Nova Fronteira da Lingua portuguesa. 2 ed. Rio de Janeiro: Nova Fronteira. 1989.

R. Bras. Enferm. Brasília, v. 51, n. 3, p. 431-446, jul./set., 1998 
6. FOUCAULT, Michel. Microfísica do Poder. 3 ed, Rio de Janeiro: Graal, 1982.

7. Vigiar e punir. 6. ed., Petrópolis: Vozes, 1987.

8. A arqueologia do Saber. 4 ed. Rio de Janeiro: Forense Universitária, 1995.

9. GOIS, C.. Dicionário de raízes e cognatos da língua portuguesa. Rio de Janeiro: Francisco Alves, 1921.

10. MARILLAC, Santa Luiza de. Correspondências e escritos. Datados de 1640 a 1660. Trad. Irmã Lucy Cunha. São Paulo, Ed. Legie Summa Ltda, 1983.

11. MOLLAT, Michel. Os pobres na idade média. Rio de Janeiro: Campus, 1989.

12. VAESSEN, Padre Guilherme. Santa Luiza de Marillac suas filhas e suas Senhoras de Caridade. Salvador: Ed. Mensageiros de Fé., 1949. 